\title{
ANALISIS PERBANDINGAN KINERJA ANTARA MEDIA KABEL SERAT OPTIK DENGAN KABEL TEMBAGA PADA ROUTER MIKROTIK
}

\author{
Eka Setya Wijaya \\ Program Studi Teknologi Informasi, Fakultas Teknik, Universitas Lambung Mangkurat \\ JL. Hasan Basry, Kayu Tangi, Banjarmasin \\ e-mail: ekasw@ulm.ac.id
}

\begin{abstract}
ABSTRAK
Kabel kawat tembaga dan kabel serat optik adalah dua media komunikasi yang banyak digunakan dalam membangun jaringan komunikasi data di era modern saat ini. Untuk administrator jaringan, memilih jenis kabel yang tepat dalam membangun jaringan adalah suatu keharusan. Beberapa faktor, baik internal maupun eksternal dapat mempengaruhi kinerja peralatan jaringan. Dalam penelitian ini dilakukan analisis komparatif tentang perbedaan kinerja antara penggunaan kabel serat optik dan kabel kawat tembaga yang mampu mentransfer data 1 Gigabit per detik. Analisis pengukuran kinerja mencakup kemampuan untuk mentransfer data dari dua node seperti latensi, throughput, dan packet loss. Untuk pengujian latency dan throughput dilakukan dengan mengirimkan sebanyak 65.000 data untuk 30 kali untuk setiap media. Sedangkan untuk paket loss testing dilakukan dengan mengirimkan 10.000 data dalam 1 menit menggunakan bandwidth uji pada router Mikrotik. Dari hasil pengujian, dapat dilihat bahwa terdapat perbedaan kestabilan kinerja kabel kawat tembaga dan kabel serat optik. Semakin tinggi suhu udara, packet loss, dan latency akan meningkat. Adapun nilai throughput, suhu hanya mempengaruhi nilai throughput pada kabel serat optik dan tidak mempengaruhi throughput pada kabel kawat tembaga.
\end{abstract}

Kata Kunci: kawat tembaga, latency, packet loss, serat optic, throughput.

\begin{abstract}
Copper wire and fiber optic cable are two communication media that are widely used in building data communication networks in the modern era. For network administrators, choosing the right type of cable in building a network is a must. Several factors, both internal and external, can affect the performance of network equipment. In this study, a comparative analysis of performance differences between the use of fiber optic cables and copper wire cables which are capable of transferring 1 Gigabit per second of data is conducted. Performance measurement analysis includes the ability to transfer data from two nodes such as latency, throughput, and packet loss. The latency and throughput testing are done by sending as many as 65,000 data for 30 times for each media. Whereas for packet loss testing is done by sending 10,000 data in 1 minute using the test bandwidth on the Mikrotik router. From the test results, it can be seen that there are differences in the stability of the performance of copper wire and fiber optic cables. The higher the air temperature, packet loss, and latency will increase. As for the throughput value, temperature only affects the value of throughput in fiber optic cables and does not affect the throughput of copper wire cables.
\end{abstract}

Keywords: copper wire, fiber optics, latency, packet loss, throughput.

\section{Pendahuluan}

ADANYA performansi jaringan yang lebih baik dibandingkan dengan menggunakan media wireless menjadikan kabel sebagai solusi alternatif pilihan media komunikasi yang dapat digunakan untuk menghubungkan antar perangkat dalam membangun jaringan komputer. Media komunikasi memiliki kelemahan dan keunggulan yang berbeda-beda. media komunikasi yang digunkan di bidang jaringan antara lain disebutkan di (Telkomnika vol.7, N0. 1, April 2009): kabel telepon, kabel UTP (Unshielded Twisted Pair), serat optik, satelit dan gelombang radio [1].

Untuk skala jaringan menengah, penggunaan kabel UTP lebih sering digunakan daripada kabel serat optik. Selain relatif lebih murah, dari sisi instalasi jaringan juga lebih mudah. Namun dalam proses instalasi jaringan dengan menggunakan kabel UTP saat ini masih terbatas pada jarak yang direkomendasikan terhadap panjang kabel maksimal yang bisa digunakan untuk menghubungkan antar dua perangkat. Pada penelitian sebelumnya diperoleh hasil bahwa pada penggunaan kabel UTP, panjang kabel maksimal yang diperbolehkan sebesar 361 feet (110 meter) [3].

Pada skala yang lebih jauh, jaringan komputer dapat dibangun menggunakan serat optik. Serat optik adalah suatu media komunikasi yang berfungsi untuk mentransmisikan informasi melalui media cahaya. Serat optik memiliki beberapa kelebihan, yaitu pengiriman datanya yang lebih cepat, lebih akurat, dan relatif lebih stabil terhadap 
perubahan kondisi lingkungan dibandingkan kabel tembaga. Sementara kelemahan serat optik, yaitu terjadinya loss atau redaman serat optik yang mengakibatkan data hilang atau terhambat dalam pengirimannya (Rambe,2003). Namun, kelebihan-kelebihan serat optik seperti yang telah dijelaskan diatas terkendala jika mengalami gangguan dari kondisi lingkungan yang tidak normal, misalnya kondisi suhu lingkungan. Pada kajian sebelumnya oleh (Sujito $\mathrm{dkk}, 2012$ ) mengenai pengaruh perubahan temperatur terhadap rugi daya serat optic singlemode SMF-28 dengan variasi suhu berkisar antara $-14^{\circ} \mathrm{C}$ hingga $30^{\circ} \mathrm{C}$ untuk berbagai panjang gelombang yang berbeda yakni $1310 \mathrm{~nm}$, $1490 \mathrm{~nm}, 1550 \mathrm{~nm}, 1625 \mathrm{~nm}$. Hasil penelitian menunjukkan pada variasi suhu yang diberikan untuk berbagai panjang gelombang yang berbeda terdapat redaman yang bervariasi pula. Hal ini menunjukkan bahwa adanya pengaruh variasi suhu dan panjang gelombang yang digunakan juga berpengaruh terhadap nilai redaman daya (loss) yang dihasilkan oleh serat optik [2].

Mulai maraknya penggunaan kabel serat optik FTTH untuk jaringan bersekala menengah di luar ruangan, membuat penulis tertarik untuk melakukan uji perbandingan unjuk kerja jaringan yang menggunakan media kabel serat optik dengan jaringan yang menggunakan media kabel tembaga dalam hal ini Twisted Pair Cat6.

Belum ada penelitian yang secara khusus membahas tentang uji perbandingan unjuk kerja jaringan yang menggunakan kabel serat optik dengan kabel UTP, penelitian ini merupakan penelitian lanjutan yang sudah dilakukan oleh penulis sebelumnya yaitu pengukuran unjuk kerja jaringan pada penggunaan kabel UTP dan STP yang menyimpulkan bahwa jarak maksimal untuk penggunaan kabel UTP adalah 110 meter.

\section{LANDASAN TEORI}

Saat ini pemanfaatan kabel pada jaringan komputer sebagai media utama dalam melakukan transmisi paket data masih banyak digunakan meskipun sudah ada alat alternatif lain yaitu menggunakan jaringan wireless. Alasan yang mendasari jenis jaringan ini masih banyak digunakan secara luas karena biaya untuk membagun jaringan kabel masih jauh lebih murah dibanding membangun jaringan wirelees. Kabel jaringan cenderung lebih stabil dalam mentransmisikan data dan jaringan komputer juga cenderung tidak terpengaruh cuaca. Kabel jaringan yang umum digunakan saat ini terdiri dari beberapa jenis yang mana setiap jenis kabel memiliki karakteristiknya masing masing.

\section{A. Serat Optik}

Serat optik (optical fiber) adalah saluran transmisi atau sejenis kabel yang terbuat dari serat kaca atau plastik yang sangat halus dan lebih kecil dari sehelai rambut, dan dapat digunakan untuk mentransmisikan sinyal cahaya dari suatu tempat ke tempat lain. Sumber cahaya yang digunakan biasanya adalah laser atau LED (light emitting diode). Kabel ini berdiameter lebih kurang 120 mikrometer. Cahaya yang ada di dalam serat optik tidak keluar karena indeks bias dari kaca lebih besar daripada indeks bias dari udara, karena laser mempunyai spektrum yang sangat sempit. Kecepatan transmisi serat optik sangat tinggi sehingga sangat bagus digunakan sebagai saluran komunikasi.[11].

Dalam penggunaannya sebagai media untuk membangun jaringan komunikasi komputer, serat optik memiliki karakteristik sebagai berikut:

1. Mahal

2. Bandwith lebar

3. Hampir tidak ada resistansi dan loss

4. Tidak bias di tengah

5. Merupakan salah satu kabel utama masa depan.

Ada 3 buah tipe dasar dari serat optik, yaitu: fiber multimode-graded-index, fiber multimodestep-index dan fiber step-index single-mode. Sebuah serat multimode dapat merambatkan ratusan moda cahaya pada waktu yang bersamaan, sementara pada serat bertipe single-mode hanya mampu merambatkan satu moda seperti yang ditunjukkan pada Gambar 1.

Penggunaan serat optik sebagai media komunikasi data memiliki beberapa kelemahan karena rentan terhadap beberapa masalah berikut:

1. Attenuasi; merupakan karakteristik dari sinyal yang akan melemah ketika melewati jarak tertentu

2. Dispersi; yang dapat berakibat terjadinya penyebaran pulsa cahaya akan sehingga menyebabkan pengiriman data tidak optimal.

3. Non-linearitas; salah satu dari efek non-linearitas disebabkan karena pencampuran empat gelombang. Pencampuran empat gelombang (Four Waves Mix) adalah proses optik non-linear di mana dua gelombang lainnya dihasilkan oleh interaksi dua panjang gelombang. Pencampuran empat gelombang menggambarkan interaksi gelombang melalui polarisasi non-linear. Generasi gelombang memiliki frekuensi yang sama tetapi vektor gelombang yang berbeda adalah karena indeks bias non-linier dari medium. 


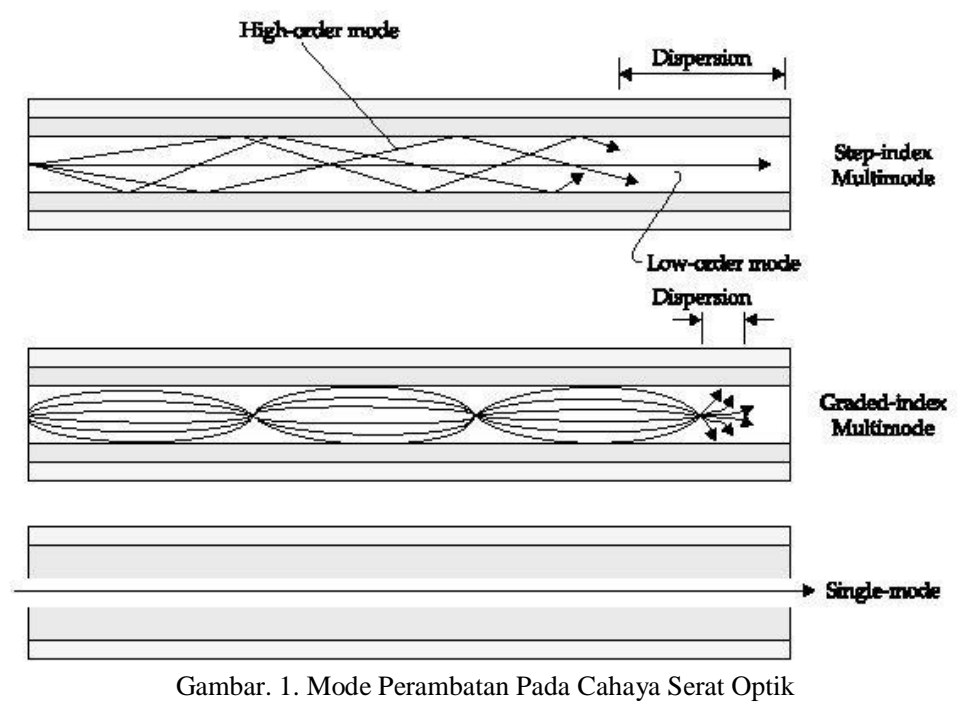

\section{B. Kabel Tembaga Twisted Pair}

Kabel twisted pair merupakan jenis kabel yang terdiri dari 8 buah kawat yang dilapisi insulator yang berbedabeda warna [1]. Kabel twisted pair yang paling sering digunakan adalah Unshielded Twisted Pair (UTP). Kabel UTP umumnya terbuat dari bahan penghantar tembaga, mempunyai isolasi dari plastik \& terbungkus oleh bahan isolasi yang dapat melindungi dari api dan juga kerusakan fisik, kabel UTP sendiri terdiri dari 4 pasang inti kabel yang saling berbelit dimana masing-masing pasang mempunyai kode warna berbeda. Atau definisi kabel UTP adalah suatu jenis kabel yang dapat dipakai untuk membuat jaringan komputer, berupa kabel yang pada bagian dalamnya berisikan 4 pasang kabel. Kabel Twisted Pair Cable ini terbagi ke dalam 2 jenis diantaranya, Shielded dan Unshielded. Shielded adalah jenis dari kabel UTP yang memiliki selubung pembungkus, sedangkan unshielded adalah jenis yang tidak mempunyai selubung pembungkus. Untuk koneksinya kabel jenis ini memakai konektor $R J-45$.

Jenis kabel UTP dimulai dari category3 (Cat3). Jenis kabel ini diperuntukkan untuk Ethernet dengan tipe IOBASE-T. Bandwidth yang diberikan oleh Ethernet tipe ini adalah $10 \mathrm{Mbps}$. Kemudian muncul tipe Ethernet yang lain yaitu 100BASE-TX yang memberikan bandwidthsebesar 100 Mbps. Penggunaan Ethernet tipe 100BASE-TX menurut penjelasan tabel 2 harus menggunakan tipe kabel yang berbeda dengan tipe Ethernet 1OBASE-T. Jenis kabel UTP category5 (Cat5) sangat cocok untuk digunakan pada tipe Ethernet 100BASE-TX. Hal ini dikarenakan dengan semakin besar bandwidthyang diberikan oleh sebuah interfaceEthernet, maka spesifikasi frekuensi yang digunakan oleh jenis kabel UTP juga harus lebih besar. Begitupula dengan perkembangan jenis kabel UTP yang lain, dimulai dari cat5e, cat6, cat6a, sampai cat7. Nilai frekuensi yang digunakan pada jenis kabel UTP tersebut semakin besar.

Dalam menghubungkan antar dua komputer dengan menggunakan kabel UTP diperlukan peran dari NIC (Network Interface Card). Dalam interface card tersebut diperlukan peran protokol agar aliran bit data dapat dikirimkan dari komputer pengirim ke penerima. Saat ini, protokol yang banyak digunakan adalah Ethernet. Semua tipe Ethernet mempunyai jarak maksimal panjang kabel yang sama yaitu sebesar 100 meter. Untuk tipe Ethernet 1000BASE-TX dengan bandwidth interface sebesar $1 \mathrm{Gbps}$, jenis kabel UTP yang digunakan adalah category6 (cat6). Dengan berasumsi bahwa kabel UTP Cat6 bisa mengalirkan bandwith sebesar 1 Gbps, maka kemampuan kabel ini sebanding dengan kemampuan kabel Serat optik FTTH singlemode.

\section{Latency}

Latency merupakan waktu yang dibutuhkan data untuk menempuh jarak dari asal ke tujuan [4]. Dalam proses pengukuran biasanya latency diukur dengan menggunakan waktu bolak-balik (round trip time/RTT). Agar nilai latency yang dihasilkan pada saat proses pengukuran bisa dikategorikan, maka digunakan standar pembanding. Pada penelitian ini digunakan standar acuan yang dikeluarkan oleh ITU-T seperti pada Tabel I.

TABEL I

STANDARISASI NILAI LATENCY VERSI ITU-T [5]

\begin{tabular}{cc}
\hline \hline Kategori & Latency $(\mathrm{ms})$ \\
\hline Baik & $<150$ \\
Cukup & 150 \\
Buruk & $>400$ \\
\hline \hline
\end{tabular}


Berdasarkan keterangan tabel 1, nilai latency dikatakan baik apabila hasil pengukuran nilai latency dari dua buah perangkat yang terhubung kurang dari $150 \mathrm{~ms}$.

\section{Packet loss}

Packet loss merupakan sejumlah paket data pada jaringan komputer yang hilang selama proses trannsmisi [3]. Parameter packet loss dalam proses penelitian akan digunakan sebagai acuan dalam menentukan jenis kabel yang direkomendasikan sesuai standar, dimana acuan yang digunakan adalah standar dari TiPhone TR 101 seperti pada Tabel II.

TABLE II

STANDARISASI PACKET LOSS VERSI TIPHONE TR 101329 [6]

\begin{tabular}{cc}
\hline \hline Kategori & Packet loss $(\%)$ \\
\hline Sangat baik & $0 \leq \mathrm{pl}<3$ \\
Baik & $3 \leq \mathrm{pl}<15$ \\
Cukup & 15 \\
Buruk & $\geq 25$ \\
\hline \hline
\end{tabular}

\section{E. Throughput}

Throughput merupakan ukuran keberhasilan secara aktual dalam pengiriman paket data pada jaringan komputer oleh suatu perangkat, dilihat dari berapa banyak paket data yang berhasil dikirimkan dalam kurun waktu satu detik. Nilai dari throughput diukur dengan satuan bit per second (bps) [4]. Berikut persamaan untuk menghitung nilai throughput [7]:

$$
\text { Throughput }=\frac{\sum \text { data yang dikirim }(\text { bit })}{\text { waktu pengiriman data }(s)}
$$

Dari persamaan (1) diatas nilai throughput berbanding terbalik dengan nilai latency. Apabila diketahui nilai latency besar, maka nilai throughput akan mengecil. Begitu pula sebaliknya. Dengan kata lain, jika diinginkan nilai throughput yang bagus, maka salah satu parameter yang harus diusahakan baik adalah dengan mengatur nilai latency yang kecil.

\section{METODE PENELITIAN}

Ada beberapa tahapan dari metode yang digunakan dalam penelitian ini. Mulai dari persiapan alat dan bahan, instalasi peralatan sampai pengolahan data untuk mendapatkan hasil berupa informasi yang kemudian akan dianalisis menjadi sebuah kesimpulan.

\section{A. Alat dan Bahan}

\section{a. Perangkat Lunak}

1. Mikrotik Router OS, Sistem Operasi yang digunakan pada sepasang perangkat router sebagai node yang terhubung oleh media kabel tembaga dan kabel serat optik.

2. Bandwidth Test, Software atau tools yang dipasang di kedua sisi router dan digunakan sebagai pengumpulan trafik data yang dilewatkan pada kedua media jaringan.

b. Perangkat Keras

1. Kabel Serat Optik FTTH Singlemode Outdor 100 meter, digunakan sebagai objek media yang diuji, seperti pada Gambar 2.

2. Kabel Twisted Pair Cat6 Outdoor 100 meter, digunakan sebagai objek media yang diuji, seperti pada Gambar 2.

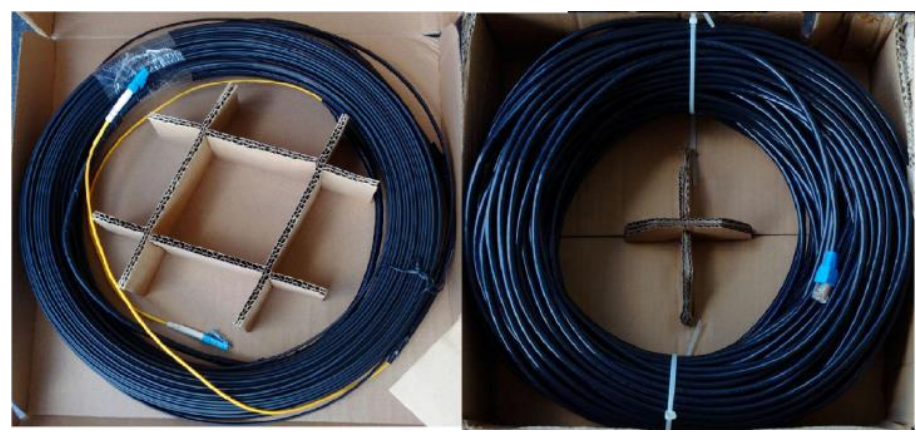

Gambar. 2. Kabel Serat Optik Dan Kabel Tembaga Yang Digunakan 
3. Mikrotik RB960PGS sebanyak 2 unit, berfungsi sebagai perangkat yang melakukan proses pengiriman trafik data sebagai uji terhadap kedua jenis media tersebut dengan memasang di tiap ujung kabel.

4. Mikrobits SFP Bidirectional Pair- 1G-BD-SM sebanyak 2 unit, digunakan sebagai konverter sinyal digital menjadi sinyal cahaya yang akan dilewatkan pada kabel dari kabel.

\section{B. Metode Pengumpulan Data}

a. Observasi

Pengumpulan data secara observasi didapatkan melalui bantuan tools Bandwith Test yang ada di router Mikrotik. Data bersumber dari trafik yang dilewatkan pada kedua media jaringan dengan mengirimkan paket data antar router serta mengamati jaringan yang dibuat menggunakan skema topologi peer-to-peer antar dua router, baik menggunakan kabel serat optik dan kabel tembaga seperti pada gambar 3 .

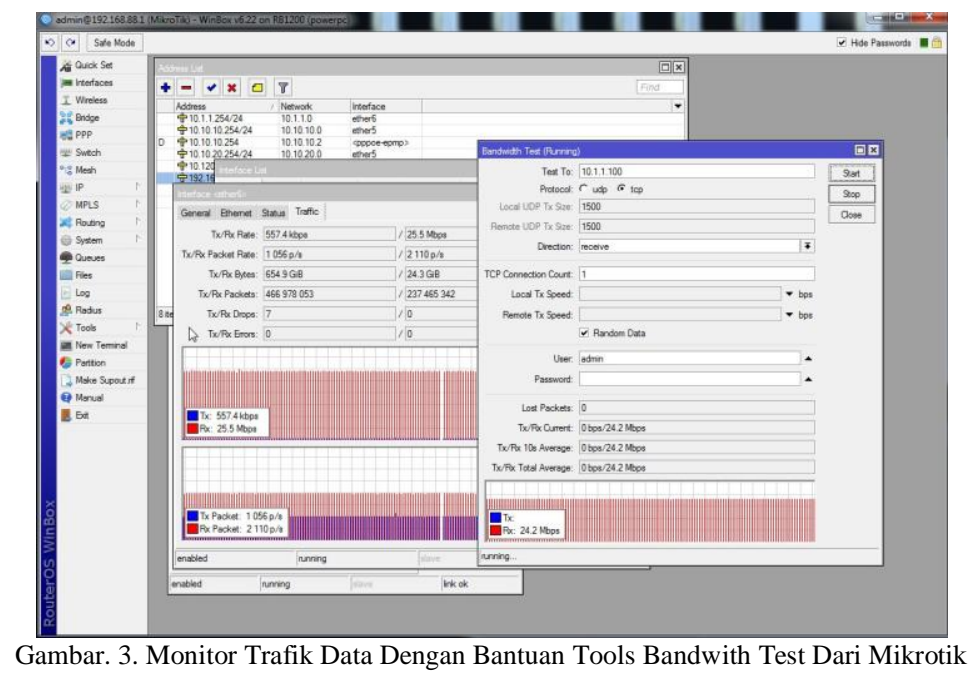

Sesuai hasil penelitan sebelumnya, jarak kabel yang optimal digunakan untuk menghubungkan antar dua node dalam hal ini router adalah 100 meter, maka panjang kedua kabel yang digunakan pada penelitian ini adalah 100 meter yang kemudian dilakukan pengujian untuk beberapa nilai, yaitu latency, throughput, dan packet loss. Router yang digunakan mempunyai jenis, spesifikasi dan konfigurasi yang sama. Kedua jenis kabel tersebut dipasang dengan cara membentangan di luar ruangan sehingga terpapar langsung dengan kondisi cuaca yang terjadi saat itu seperti yang ditunjukkan dalam proses instalasi pada Gambar 4.

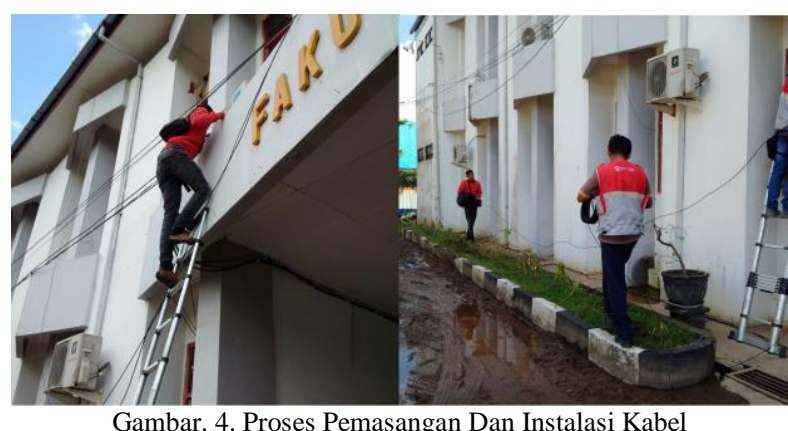

Pengukuran nilai dari ketiga parameter tersebut dilakukan pada dua arah yaitu posisi router 1 ke router 2 untuk kabel tembaga Twisted Pair dan dari router 2 ke router 1 untuk kabel Serat Optik, seperti yang ditunjukan pada Gambar 5. Dalam menentukan nilai dari parameter unjuk kerja jaringan, yaitu latency, throughput, dan packet loss dilakukan dengan cara mengirimkan paket UDP antar router setiap enam puluh menit sekali selama kurang lebih tiga bulan. Setelah data hasil pengukuran didapatkan, dilakukan pengolahan data hasil dari proses pengukuran.

Setiap ujung kedua kabel terhubung ke router Mikrotik yang akan mencatat seluruh aktifitas hasil kinerja dari pengiriman trafik data kedua kabel tersebut yang meliputi pengujian nilai latency/delay waktu proses dalam sekali pengiriman data, throughput atau besar data yang bisa dikirimkan dalam sekali pengiriman serta packet loss atau jumlah data yang gagal dalam proses pengiriman. Hasilnya akan dicatat dalam log router dan akan dikirim secara otomatis melalui email setiap 5 jam untuk dilakukan pengamatan. 


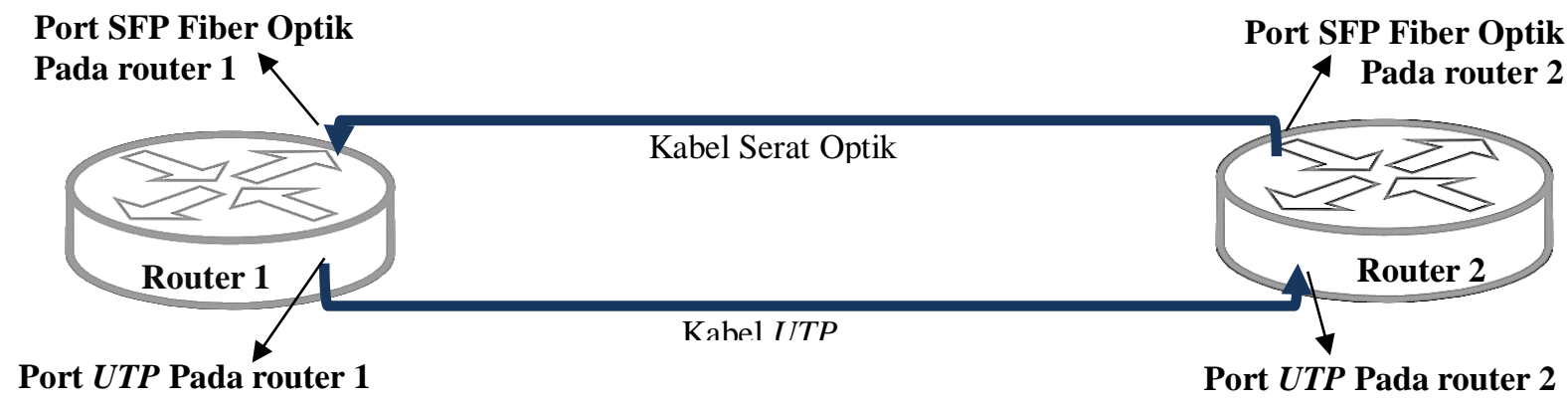

Gambar. 5. Model Jaringan Peer To Peer Antar Router Untuk Metode Penelitian

1. Mencari Nilai Latency

Untuk mendapatkan nilai latency pada penelitian ini, digunakan tools Ping pada Mikrotik. Ping adalah salah satu perintah yang paling umum digunakan dan dikenal. Para administrator jaringan selalu menggunakan tools ini untuk menguji apakah suatu host tertentu dapat dijangkau melalui jaringan dan untuk mengukur waktu yang diperlukan untuk pulang-pergi suatu paket yang dikirim dari host awal ke host tujuan. Output dari Ping dapat menampilkan waktu minimum, rata-rata dan maksimum yang digunakan untuk pengiriman paket data dari awal sampai kembali. [9]

Perintah Ping diatur dengan membuat pengiriman hingga 65.000 paket data sebanyak 30 kali perulangan selama disetiap sesi pengujian. Skrip konfigurasi ping untuk pengukuran nilai latency adalah sebagai berikut,

:global awal;

:global akhir;

:execute $\{/$ ping 192.168.1.2 count $=30$ size $=65000$ src-address $=192.168 .1 .1\}$ file $=$ PINGLAN

:delay 00:00:35

:set awal [:find [/file get PINGLAN.txt contents] "sent=30"];

:set akhir [:find [/file get PINGLAN.txt contents] "VrVn\rn"];

:log info [:pick [/file get PINGLAN.txt contents] \$awal \$akhir];

2. Mencari Nilai Packet loss

Pada router mikrotik telah tersedia sebuah tools yaitu Bandwidth Test untuk mengukur jumlah packet loss. Konfigurasi Bandwidth Test diatur dengan mengirimkan jumlah paket data sebanyak 10,000 data menggunakan protokol UDP dengan kecepatan 1.000Mbps (1Gbps) dalam waktu 60 detik. Skrip konfigurasi untuk mengukur nilai packet loss adalah sebagai berikut,

:global tx

:global rx

:global

Itool bandwidth-test 192.168.1.2 direction=both duration $=60$ s protocol $=u d p$ local- $u d p-t x$-size $=10000$ remote- $u d p$-tx-size $=10000$ local-tx-speed $=1000000000$ remote-t $x$-speed $=1000000000 \mathrm{do}=\{$

:set tx $\$ "$ tx-total-average"

:set $r x \$ " r x$-total-average"

:set lp \$"lost-packets"

\}

:log info ("tx|".\$tx."|rx|".\$rx."|PL|".\$lp

3. Mencari Nilai Throughput

Untuk mendapatkan nilai throughput digunakan pula tools Bandwidth Test selama percobaan. Bandwith Test diatur dengan membuat proses pengiriman 10.000 paket data menggunakan protokol UDP dengan kecepatan transfer data 1.000Mbps (1 Gbps) dalam waktu 60 detik. Script konfigurasi Bandwith Test untuk mendapatkan nilai throughput adalah sebagai berikut,

:global tx

:global rx

:global

Itool bandwidth-test 192.168.1.2 direction=both duration=60s protocol=udp local-udp-tx-size=10000 remote- $u d p$-t $x$-size $=10000$ local-t $x$-speed $=1000000000$ remote-t $x$-speed $=1000000000$ do $=\{$

set tx $\$ " t x$-total-average" 


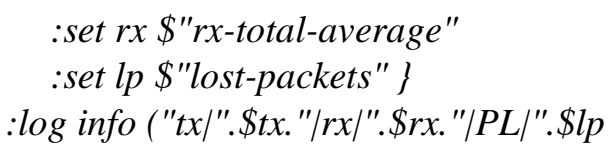

\section{b. Studi Pustaka}

Pengumpulan data dengan membaca serta mempelajari dokumen-dokumen, literatur, jurnal, dan buku-buku serta sumber lainnya yang berhubungan dengan unjuk kerja jaringan kabel tembaga dan jaringan kabel serat optik.

\section{Metode Pengolahan Data}

Trafik data yang tercatat pada file log di router Mikrotik diproses dengan tools pengolah data Microsoft Excel untuk mendapatkan nilai-nilai dari ketiga parameter yang diperlukan yaitu nilai latency, packet loss dan throughput. Data kemudian kemudian dinormalisasi agar memiliki ukuran yang sama untuk setiap parameter.

Data yang dihasilkan oleh tools Bandwith Test pada catatan log yang tersimpan di router Mikrotik adalah sebagai berikut,
May $/ 24 / 2018$ 10:03:35 script, info sent $=30$ received $=30$ packet-loss $=0 \%$ min $r t t=3 \mathrm{~ms}$ avg-rtt $=3 \mathrm{~ms}$ max-rtt $=4 \mathrm{~ms}$
May $/ 24 / 2018$ 11:03:35 script,info sent $=30$ received $=30$ packet - loss $=0 \%$ min $-r t t=3 \mathrm{~ms}$ avg-rtt $=3 \mathrm{~ms}$ max $-\mathrm{rtt}=20 \mathrm{~ms}$
May/24/2018 12:03:35 script,info sent $=30$ received $=30$ packet-loss $=0 \%$ min-rtt $=3 \mathrm{~ms}$ avg-rtt $=3 \mathrm{~ms}$ max $-\mathrm{rtt}=3 \mathrm{~ms}$
May/24/2018 13:03:35 script, info sent $=30$ received $=30$ packet-loss $=0 \%$ min-rtt $=3 \mathrm{~ms}$ avg-rtt $=3 \mathrm{~ms}$ max $-\mathrm{rtt}=3 \mathrm{~ms}$
May $/ 24 / 2018$ 14:03:35 script, info sent $=30$ received $=30$ packet-loss $=0 \%$ min-rtt $=3 \mathrm{~ms}$ avg-rtt $=3 \mathrm{~ms}$ max-rtt $=3 \mathrm{~ms}$

Untuk validitas dan keakuratan hasil, parameter yang dibandingkan untuk nilai latency adalah max-rtt (waktu pulang pergi). Dari file log yang tercatat diambil nilai max-rtt rata-rata untuk dijadikan nilai latency per hari dan kemudian dilakukan normalisasi data seperti pada Tabel III,

TABEL III

TOtal RATA-RATA Nilai LATENCy PER HARI

\begin{tabular}{ccc}
\hline \multirow{2}{*}{ Tanggal } & \multicolumn{2}{c}{ Latency (ms) } \\
& Kabel Tembaga (Twisted Pair) & Kabel Serat Optik (FTTH) \\
\hline May/17/2018 & 13.80 & 3.91 \\
May/18/2018 & 15.42 & 3.88 \\
May/19/2018 & 14.17 & 5.00 \\
May/20/2018 & 14.21 & 4.79 \\
May/21/2018 & 13.50 & 3.91 \\
May/22/2018 & 3.42 & 4.92 \\
May/23/2018 & 10.19 & 3.70 \\
May/24/2018 & 13.13 & 4.96 \\
May/25/2018 & 13.54 & 4.25 \\
May/26/2018 & 14.00 & 4.79 \\
May/27/2018 & 15.00 & 3.78 \\
$\ldots$ & $\ldots$. & $\ldots$ \\
\hline \hline
\end{tabular}

Sedangkan data yang dihasilkan oleh tools Ping pada catatan log yang tersimpan di router Mikrotik adalah sebagai berikut,

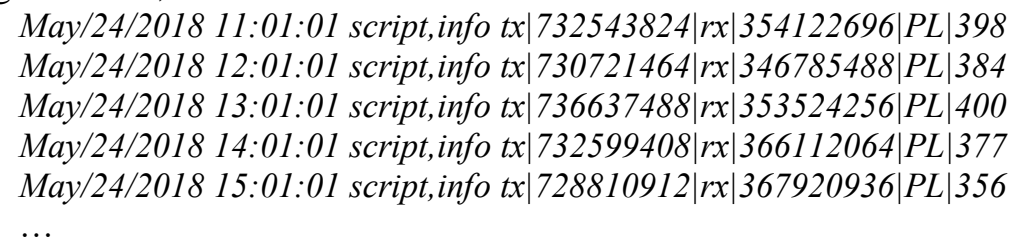

Nilai yang akan dibandingkan untuk pengukuran parameter throughput adalah nilai $r x . R x$ adalah jalur penerimaan data (perpindahan data) dari satu node ke node lain. $R x$ biasa disebut received, yang berguna menangkap jumlah data yang dikirim oleh transmitter $(t x)$. Sedangkan untuk parameter packet loss mengambil nilai $P L$ yang langsung tersedia pada catatan log. Dari file log yang tercatat, diambil nilai $r x$ terendah per hari agar mendapatkan hasil yang akurat sedangkan untuk packet loss adalah nilai rata-rata $P L$ sebagai nilai packet loss per hari, kemudian dilakukan normalisasi data seperti pada Tabel IV, 
TABLE IV

TOTAL RATA-RATA JUMLAH PACKETS LOSS DAN NILAI THROUGHPUT MINIMAL PER HARI

\begin{tabular}{ccccc}
\hline \hline \multirow{2}{*}{ Tanggal } & $\begin{array}{c}\text { Packet loss (packet) } \\
\text { Kabel Tembaga } \\
\text { KatP) }\end{array}$ & $\begin{array}{c}\text { Thel Serat Optik } \\
\text { (FTTH) }\end{array}$ & $\begin{array}{c}\text { Throughput (bps) } \\
\text { Kabel Tembaga } \\
(\boldsymbol{U T P})\end{array}$ & $\begin{array}{c}\text { Kabel Serat Optik } \\
\text { (FTTH) }\end{array}$ \\
\hline May/17/2018 & 716.60 & 324.27 & $86,131,820$ & $708,984,728$ \\
May/18/2018 & 642.75 & 278.25 & $86,727,475$ & $726,690,632$ \\
May/19/2018 & 660.88 & 319.63 & $86,879,372$ & $727,898,548$ \\
May/20/2018 & 657.63 & 362.21 & $86,648,590$ & $729,236,235$ \\
May/21/2018 & 818.08 & 414.74 & $119,525,526$ & $708,789,942$ \\
May/22/2018 & $1,369.38$ & 184.92 & $245,703,339$ & $446,841,902$ \\
May/23/2018 & $1,103.84$ & 325.80 & $187,061,368$ & $573,435,775$ \\
May/24/2018 & 676.88 & 437.13 & $86,494,875$ & $729,486,821$ \\
May/25/2018 & 656.04 & 519.54 & $86,589,933$ & $729,985,949$ \\
May/26/2018 & 654.38 & 441.04 & $86,412,961$ & $728,661,727$ \\
May/27/2018 & 714.00 & 408.44 & $86,857,495$ & $736,297,898$ \\
\hline \hline
\end{tabular}

\section{HASIL DAN PEMBAHASAN}

\section{A. Pengukuran Latency}

Dari data yang didapatkan, terlihat bahwa kedua kabel memiliki nilai latency yang sangat baik yaitu kurang dari 150 ms. Namun nilai latency kabel tembaga dalam hal ini Twisted Pair Cat.6 jauh lebih besar daripada kabel serat optik FTTH. Artinya kinerja kabel fiber optik dalam hal waktu kecepatan melakukan transfer data masih lebih unggul dibandingkan kabel tembaga Twisted Pair, seperti pada Gambar 6.

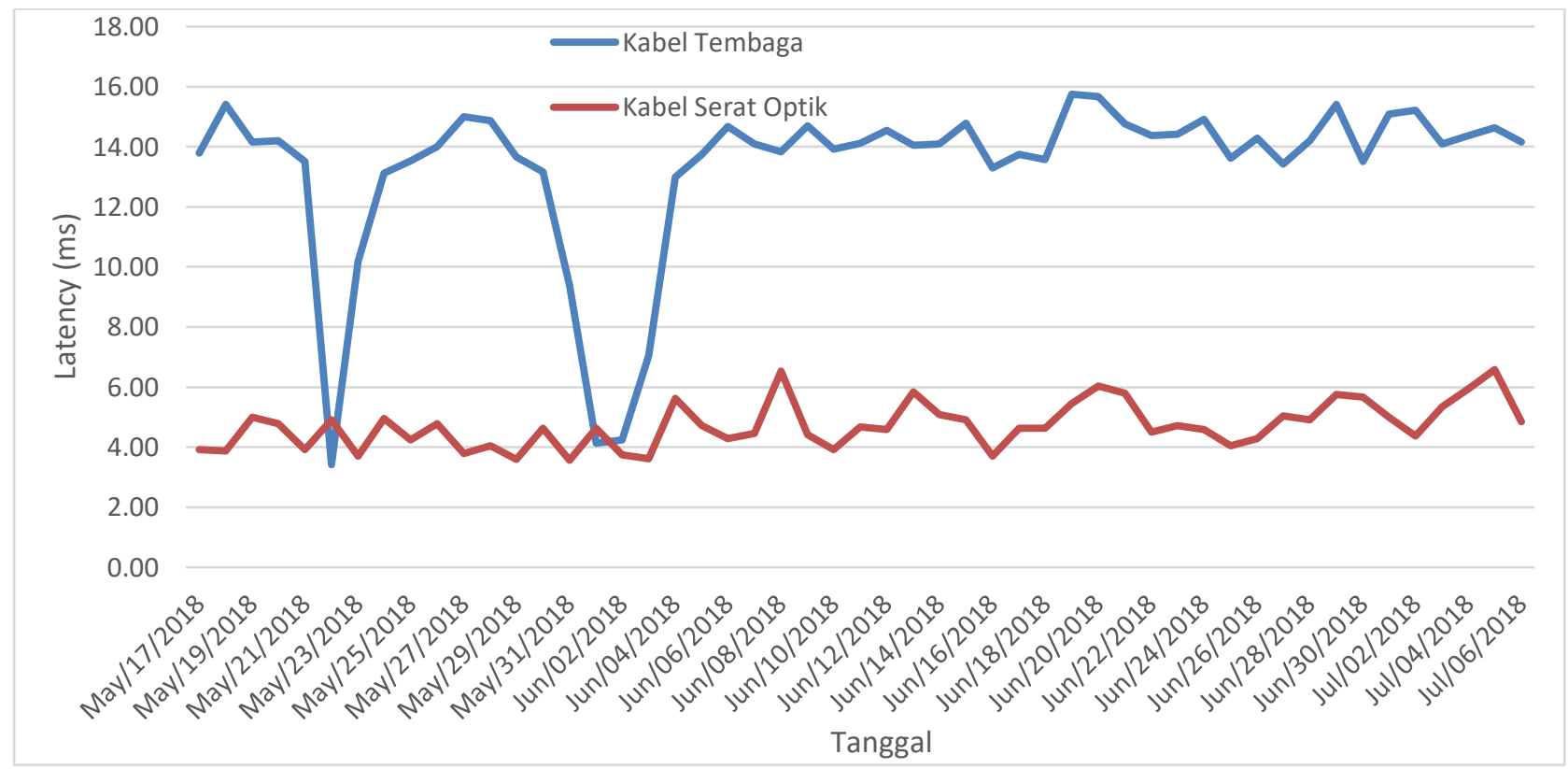

Gambar. 6. Perbandingan Nilai Latency Antara Kabel Tembaga Dengan Serat Optik

\section{B. Pengukuran Packet loss}

Dari data yang didapatkan, terlihat bahwa kedua kabel memiliki nilai packet loss yang baik yaitu kurang dari $15 \%$ data yang hilang seperti yang terlihat pada Tabel V.

TABEL V

Total RATA-RATA JUMLAH DAN PERSENTASI PACKETS LOSS PER HARI

\begin{tabular}{ccccc}
\hline \hline \multirow{2}{*}{ Tanggal } & \multicolumn{2}{c}{ Packet loss (packet) } & \multicolumn{2}{c}{ Packet loss (\%) } \\
& $\begin{array}{c}\text { Kabel Tembaga } \\
\text { (UTP) }\end{array}$ & $\begin{array}{c}\text { Kabel Serat Optik } \\
\text { (FTTH) }\end{array}$ & UTP Cat.6 & FO Single Core \\
\hline May/17/2018 & 716.60 & 324.27 & $7.17 \%$ & $3.24 \%$ \\
May/18/2018 & 642.75 & 278.25 & $6.43 \%$ & $2.78 \%$ \\
May/19/2018 & 660.88 & 319.63 & $6.61 \%$ & $3.20 \%$ \\
May/20/2018 & 657.63 & 362.21 & $6.58 \%$ & $3.62 \%$ \\
May/21/2018 & 818.08 & 414.74 & $8.18 \%$ & $4.15 \%$ \\
May/22/2018 & $1,369.38$ & 184.92 & $13.69 \%$ & $1.85 \%$
\end{tabular}




\begin{tabular}{ccccc}
\hline \hline \multirow{2}{*}{ Tanggal } & \multicolumn{2}{c}{ Packet loss (packet) } & \multicolumn{2}{c}{ Packet loss (\%) } \\
& $\begin{array}{c}\text { Kabel Tembaga } \\
\text { (UTP) }\end{array}$ & $\begin{array}{c}\text { Kabel Serat Optik } \\
\text { (FTTH) }\end{array}$ & UTP Cat.6 & FO Single Core \\
\hline May/23/2018 & $1,103.84$ & 325.80 & $11.04 \%$ & $3.26 \%$ \\
May/24/2018 & 676.88 & 437.13 & $6.77 \%$ & $4.37 \%$ \\
May/25/2018 & 656.04 & 519.54 & $6.56 \%$ & $5.20 \%$ \\
May/26/2018 & 654.38 & 441.04 & $6.54 \%$ & $4.41 \%$ \\
May/27/2018 & 714.00 & 408.44 & $7.14 \%$ & $4.08 \%$ \\
$\ldots$ & $\ldots$ & $\ldots$ & $\ldots$ & $\ldots$ \\
\hline \hline
\end{tabular}

Namun nilai packet loss kabel tembaga dalam hal ini Twisted Pair Cat.6 jauh lebih besar daripada kabel serat optik FTTH. Artinya kinerja kabel serat optik dalam hal kegagalan melakukan pengiriman paket data masih lebih kecil dibandingkan kabel tembaga, seperti yang terlihat pada Gambar 7.

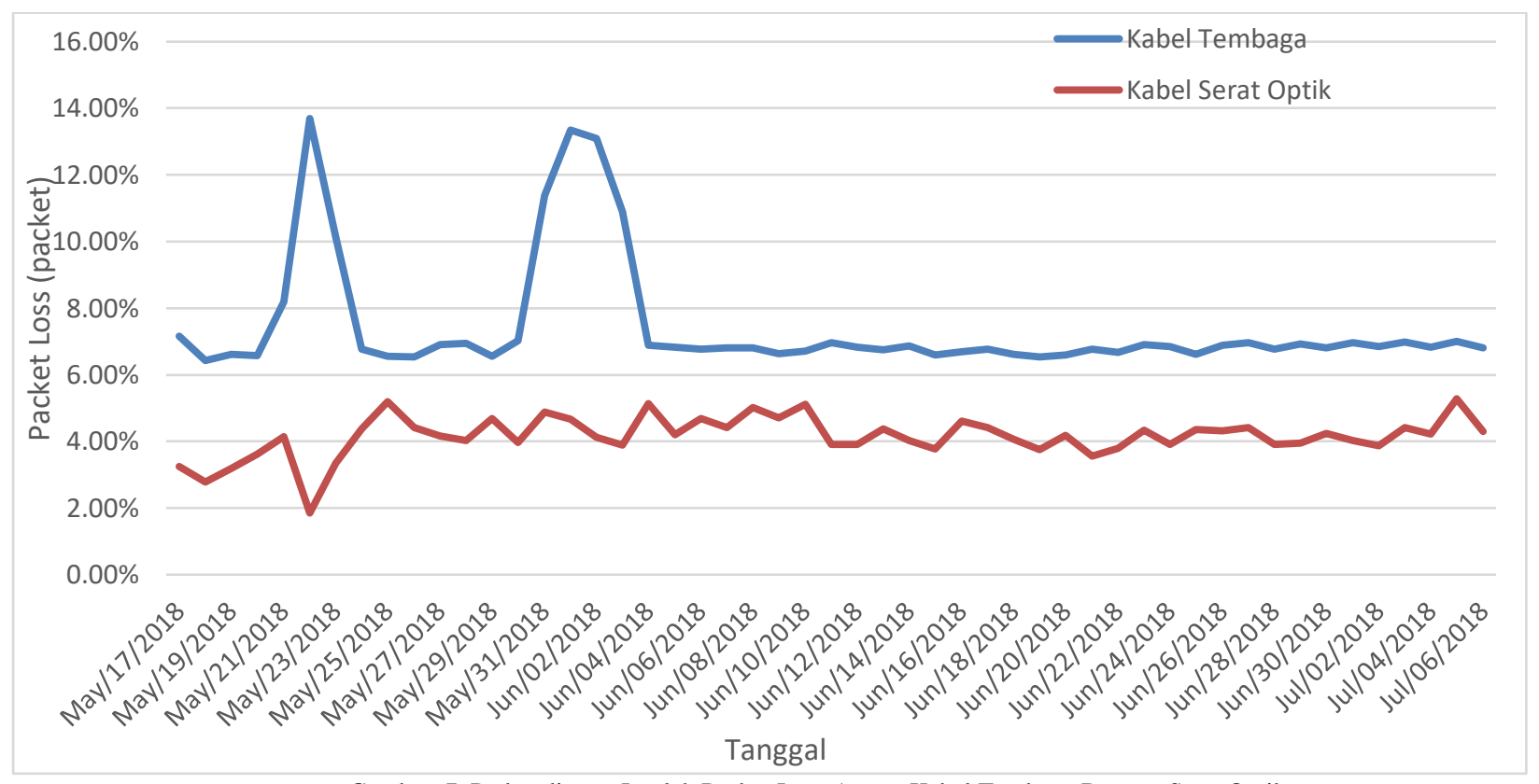

Gambar. 7. Perbandingan Jumlah Packet Loss Antara Kabel Tembaga Dengan Serat Optik

\section{Pengukuran Throughput}

Dari data yang didapatkan, terlihat bahwa nilai throughput kabel serat optik dalam hal ini jenis FTTH single core jauh lebih besar daripada kabel tembaga Twisted Pair Cat.6. Artinya kinerja kabel serat optik dalam kemampuan melakukan transfer data tiap detiknya jauh lebih besar dibandingkan kabel tembaga, seperti yang terlihat pada Gambar 8 .

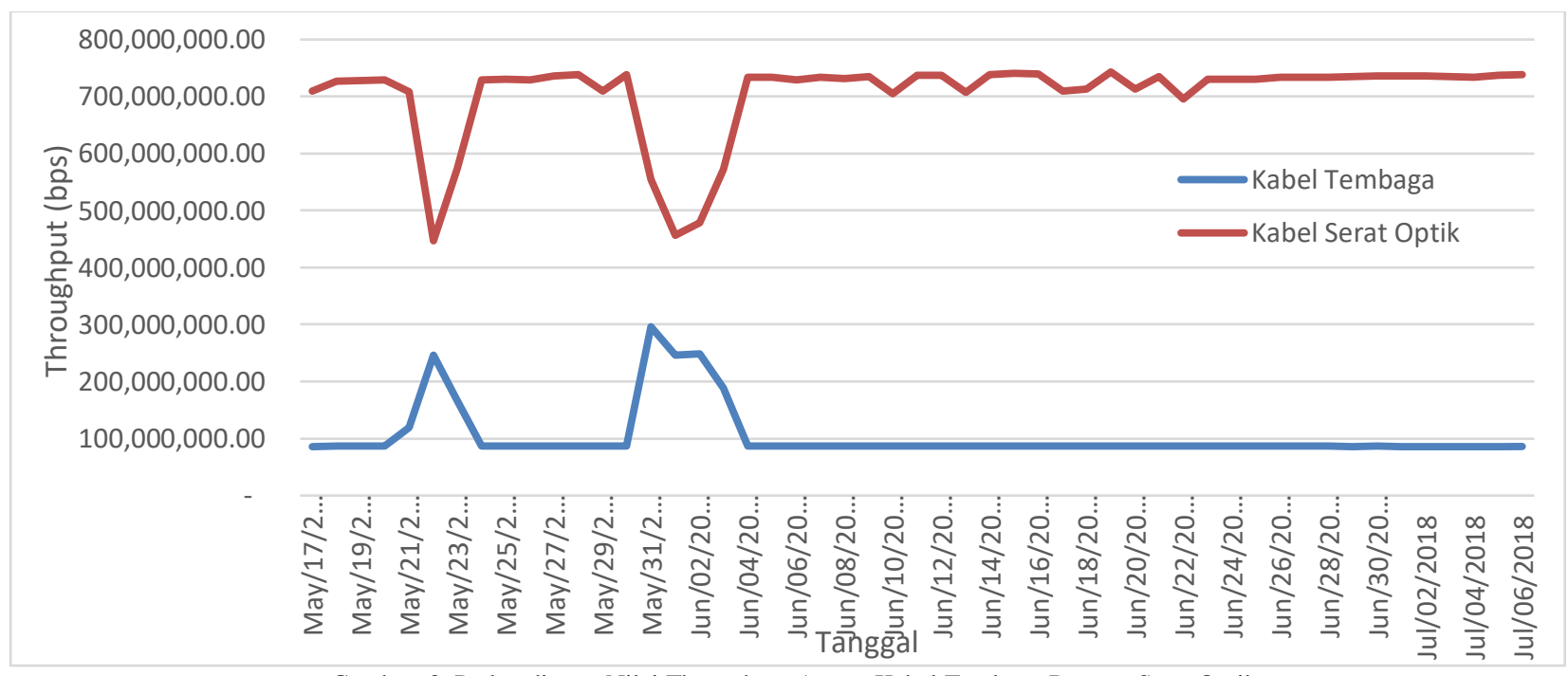

Gambar. 8. Perbandingan Nilai Throughput Antara Kabel Tembaga Dengan Serat Optik 


\section{KESIMPULAN}

Data yang dikumpulkan dari pengukuran beberapa parameter transfer data pada kabel tembaga dan kabel serat optik dengan panjang kabel 100 meter yang dihubungkan dengan dua router Mikrotik, menunjukkan bahwa kinerja kabel serat optik lebih unggul daripada kabel tembaga, baik pada jumlah packet loss, nilai latency dan nilai throughput.

Kemudian, dari hasil analisa data dapat disimpulkan bahwa pada pengukuran nilai latency dan jumlah packet loss pada kabel serat optik lebih stabil dibandingkan dengan kabel tembaga. Sedangkan untuk nilai throughput menunjukan bahwa kabel tembaga lebih stabil dibandingkan dengan kabel serat optik. Hal ini ditunjukkan oleh kemampuan kabel tembaga dalam mengirimkan jumlah paket data setiap detik yang cenderung konstan.

\section{SARAN}

Pada penelitian selanjutnya perlu dilakukan pengujian terhadap panjang kabel yang berbeda serta menambahkan parameter lain yang mungkin berpengaruh terhadap kinerja transfer data pada media kabel seperti suhu, kelembapan dan tekanan udara yang ditimbulkan dari ketinggian pemasangan kabel.

\section{DAFTAR PUSTAKA}

[1] Imam Suharjo, “Analisis Penggunaan Jaringan Kabel Listrik Sebagai Media Komunikasi Data Internet,” Telkomnika, vol. 7, no. 1, 2009.

[2] Sujito dkk. 2012. Pengaruh Perubahan Temperatur Terhadap Rugi Daya Serat Optik Singlemode SMF-28. Prosiding simposium fisika nasional xxv. Jurusan fisika FMIPA Universitas Negeri Malang.

[3] Kukuh Nugroho dan Wini Oktaviani, 2016. "Pengukuran Unjuk Kerja Jaringan Pada Penggunaan Kabel UTP Dan STP”, Seminar Nasional Teknologi Informasi dan Multimedia, STMIK AMIKOM Yogyakarta, 6-7 Februari 2016

[4] Mahmoud. F. Ahmed dan Abdallah. I. Mahmoud, 2008. "Performance Testing of Twisted Pair Cables", Hindawi Publishing Corporation: Journal of Computer Systems, Networks, and Communications, vol. 2008.

[5] Pratama, Eka, Agus, Putu, I. 2014. Handbook Jaringan Komputer. Bandung: Informatika.

[6] ITU-T. 2015. One-way transmission time ITU-T recommendation G.114, Dokumen PDF. [online]. https://www.itu.int/rec/T-REC-G.114-200305-I

[7] Tiphon. Mei 2015. TIPHON General Aspects of Quality of Service (QoS), TR 101329 v2.1.1, Dokumen PDF. [online]. http://www.etsi.org/

[8] Winarno Sugeng, Jazi Eko Istiyanto, Khabib Mustofa, Ahmad Ashari. Februari 2015. The Impact Of Qos Changes Forward Network Performance. INTERNATIONAL JOURNAL OF COMPUTER NETWORKS AND COMMUNICATIONS SECURITY, Volume 3, No.2, hal 48-53

[9] Mahmoud. F. Ahmed dan Abdallah. I. Mahmoud, 2008. "Performance Testing of Twisted Pair Cables", Hindawi Publishing Corporation: Journal of Computer Systems, Networks, and Communications, vol. 2008

[10] Febi Aditya Putra dan Yussa Ananda, "Studi Perbandingan Serat Optik Bawah Laut Dengan Kabel Tembaga Coaxial”, Jurnal Tugas Akhir Mahasiswa, Program Studi Elektro Konsentrasi Teknik Telekomunikasi, Sekolah Tinggi Teknik Harapan, 2015.

[11] Nugraha, Andi Rahman. 2006. Serat Optik. Bandar Lampung: Penerbit Andi Yogyakarta. 